\section{Schrödinger's entropy and living organisms}

SIR-Perutz (Nature 326, 555-558; 1987) may not have done justice to the argument of Boltzmann and Schrödinger about negative entropy and living organisms. Consider an isolated system that contains a living organism. The organism is an open system, exchanging mass-energy with its surroundings. It maintains itself in a stationary state of approximately constant entropy. Since the total entropy of the isolated system, which is not at equilibrium, must increase with time, the living organism must continually transfer positive entropy to its environment, or, expressed in other words, it must be a sink for negative entropy. A picturesque way to express this flux is to say that the organism feeds on negative entropy.

Where Schrödinger was misleading was in interpreting this feeding too literally by emphasizing the ordered structures of nutrients as the source of negative entropy. Actually the net negative entropy flux is the sum of all the entropy fluxes across the boundary of the organism, and the metabolism of individual nutrients may contribute positive or negative terms

The other thermodynamic considerations cited by Perutz are irrelevant to the argument in "What is Life?".

Walter Moore

916 South Mitchell Street,

Bloomington, Indiana 47401, USA

\section{Jason's golden fleece explained?}

SIR-Many explanations have been offered for why the fleece sought by Jason and the Argonauts should have been described as 'golden'. For example, Strabo' suggested that the fleece was used to trap gold washed down the river Phasis. More recently it was suggested that the term golden may have referred to the fineness, and the related value, of the fibre ${ }^{2}$

I should like to suggest instead that the fleece was literally a golden-yellow colour. This type of wool discolouration is observed in sheep which have sustained liver damage that prevents normal excretion of bilirubin in the bile. Instead, bilirubin and some related pigments appear at the skin and in the suint, resulting in a yellow staining of the wool ${ }^{3.4}$. This condition is frequently the result of ingestion of hepatoxins which are present in some plants. Many of these hepatoxins, identified notably in Lantana species, are members of a group of related pentacyclic triterpene acids ${ }^{5}$. Although the parent triterpene, oleanolic acid, does not display icterogenic activity in rabbits at the levels studied $^{5}$, in recent work it was found to be a potent toxin for cultured rat hepatocytes when administered at concentrations above 'threshold' value'.

A central feature of the golden fleece legend is that of famine. According to the story related by Apollodorus? ${ }^{7}$, the famine was contrived by a jealous stepmother in order to rid herself of her stepchildren. She persuaded her husband that the only way to end the famine was to sacrifice the children. However, they were rescued by a ram with a golden fleece. In times of drought in New Zealand, when no other feed remained, farmers have resorted to feeding their sheep on leaves from trees. Perhaps during the famine recalled in the golden fleece story, sheep would similarly have been fed on leaves from the olive tree, which was extensively cultivated in Mycenean Greece. Olive leaves are particularly rich in oleanolic acid: it has been estimated that oleanolic acid accounts for at least three per cent of the total fresh leaf weight of Olea europaea ${ }^{8}$. If a sheep is fed principally on olive leaves and, more specifically, leaves from trees that have experienced drought stress, the sheep might acquire a dose of oleanolic acid (or a related triterpenoid) sufficient to produce the liver damage that gives rise to a golden-yellow discolouration of the fleece.

Although this explanation of the golden fleece is speculative, it is at least amenable to an experimental test.

\section{Department of Physical Chemistry,}

The University of Melbourne,

Parkville, Victoria 3052, Australia

1. Strabo ix, 499

Ryder, M.L. \& Hedges, J.W. Nature 242, 480 (1973).

Rimington, C. \& Stewart, A.M. Proc. R. Soc. B110, $75-$ 91 (1932).

4. Clare, N.T. in Radiation Biology, Vol. 3 (ed. Hallaender, A.) 693-723 (McGraw-Hill, New York, 1956).

Brown, J.M.M., Rimington, C. \& Sawyer, B.C. Proc. $R$ Soc. B157, 473-491 (1963).

6. Hikino, H., Ohsawa, T., Kiso, Y. \& Oshima, Y. Planto Med. 50, 353-355 (1984)

Apollodorus i, ix, 16

8. Kubo, I \& Matsumoto, A. Experientia 40, 937-938 (1984)
.

\section{Priority claims policy and disenhancement}

SIR-In a recent editorial' you commented on the undesirability of authors describing their work as "first"; and the managing editor of the Proceedings of the National Academy of Sciences U.S.A. subsequently stated ${ }^{2}$ that the policy of that journal is not to print priority statements. The desirability of such a policy is demonstrated by a paper in the same issue of Nature by Dandanell et al. ${ }^{3}$, which was submitted on 8 September and accepted on 4 December 1986.

The authors state "Here we report that transcription initiation can be regulated from an operator site placed 1 to 5 kilobases $(\mathrm{kb})$ downstream of the deoP2 promoter (and downstream from the transcribed gene), and present the first experimental data for prokaryotic regulation at distances $>1 \mathrm{~kb}$ ". But they do not refer to our paper which appeared in Cell of 20 June $1986^{4}$ and in which it was shown that transcription of $g \ln A$ is stimulated by the presence of binding sites for the regulatory protein located $1.4 \mathrm{~kb}$ upstream or 2 $\mathrm{kb}$ downstream from the $g \ln A$ promoter.

Moreover, Dandanell et al. consider the "far" site in the deo system to be analogous to the enhancers of eukaryotic cells. However, in the eukaryotic systems and in the prokaryotic $g \ln A$ system, binding of the regulatory protein to sites far from the promoter activates the initiation of transcription, while in the deo system, binding of the regulatory protein to a site far from the promoter blocks the initiation of transcription. The analogy in this case seems to be to as yet undiscovered eukaryotic disenhancers.

Department of Biology,

Boris MAgasaniK

Massachusetts Institute of Technology, Cambridge, Massachusetts 02139, USA

1. Nature 324, 509 (1986).

2. Zwanig, F.R. Nature 325, 754 (1987)

. Dandanell, G., Valentin-Hansen, P., Løve Larsen, J.E. \& Hammer, K. Nature 325, 823-826 (1987).

4. Reitzer, L. J. \& Magasanik, B. Cell 45, 785-792 (1986)

DANDANELl et al. reply - In three articles $^{1-3}$, we have analysed gene regulation in Escherichia coli in a system under the control of a repressor that binds to multiple sites on the DNA that are separated by considerable distances, and we have discussed the striking similarity between upstream and downstream control regions in bacteria and that of enhancer elements in eukaryotic genes. With reference to the last article, we apologize for not referring to the work of Reitzer and Magasanik ${ }^{4}$ and agree that it is undesirable for authors to describe their work as "first".

We do not, however, agree with Magasanik's reflections on enhancers/disenhancers. First, the central issue is not positive versus negative control, but how proteins, present in a very low concentrations in the cell, are able to 'find' their specific targets on the enormous DNA molecule and occupy these sites efficiently. One way to overcome the competition between nonspecific and specific sites for a DNA-binding protein is DNA-looping which involves cooperative binding to two or more targets. This model is general and not restricted to positively acting proteins. Second, it is clear that a regulatory protein can act both as an activator and a repressor or that an effector can change a repressor to an activator (as in the classical prokaryotic systems, bacteriophage $\lambda$ and the ara operon). Present evidence suggests that similar phenomena also exist in eukaryotes. Thus, the E1A early antigen of human adenovirus, known to activate transcription from many promoters, is also able to function as a repressor (see ref. 5). Third, both negative and positive 